\title{
Metal-chelated cryogels for amyloglucosidase adsorption: application for continuous starch hydrolysis
}

\author{
SINEM EVLI' ${ }^{1}$, HANDE ORHAN ${ }^{1}$, PELIN SÖZEN AKTAȘ ${ }^{2}$, MURAT UYGUN $^{1,3}$ \\ and DENIZ AKTAS UYGUN ${ }^{1,3}$,* \\ ${ }^{1}$ Faculty of Science and Arts, Chemistry Division, Adnan Menderes University, Aydın, Turkey \\ ${ }^{2}$ Faculty of Science and Arts, Chemistry Division, Celal Bayar University, Manisa, Turkey \\ ${ }^{3}$ Nanotechnology Application and Research Center, Adnan Menderes University, Aydın, Turkey \\ *Author for correspondence (daktasuygun@ gmail.com)
}

MS received 27 July 2017; accepted 18 January 2018; published online 3 December 2018

\begin{abstract}
In the present work, a new metal-chelating platform was designed by using IDA as a chelating agent and $\mathrm{Cu}$ (II) as an affinity component for amyloglucosidase adsorption. Poly(AAm-GMA) cryogels were used as structural elements, while GMA monomer served reactive epoxy groups for IDA immobilization. Synthesized cryogels were characterized by FTIR, SEM and EDX studies. Pore diameter of the whole polymeric structure was 3-10 $\mu \mathrm{m}$. Effects of medium $\mathrm{pH}$, temperature, ionic strength along with amyloglucosidase concentration were also investigated for more effective amyloglucosidase adsorption and maximum adsorbed amount of amyloglucosidase was $2.93 \mathrm{mg} \mathrm{g}^{-1}$ cryogel by the optimum conditions. Reusability profile of the poly(AAm-GMA)-IDA-Cu ${ }^{2+}$ cryogels was also studied and it was found that the synthesized cryogels could be used repeatedly for many times without any significant decrease on their adsorption capacity. Also continuous hydrolysis of starch by using immobilized form of amyloglucosidase in a column system was studied.
\end{abstract}

Keywords. Amyloglucosidase; cryogel; starch hydrolysis.

\section{Introduction}

Immobilized metal affinity concept was first introduced by Porath et al [1] in 1975 by using metal-chelated sepharose for protein chromatography. Since its first practical usage, the method was adopted for affinity interaction of various biomolecules, such as therapeutic proteins, peptides, nucleic acids, hormones and enzymes [2-4]. Immobilized metal affinity chromatography (IMAC) is an affinity technique that needs a chelating ligand to capture metal ions. These chelated metal ions act as affinity ligands and establish coordinative bindings between metal ions and some amino acid residues (especially histidine and cysteine) on the surface of the biomolecules. One of the intensively used affinity ligands is iminodiacetic acid (IDA), and it makes good coordination chemistry with metal ions such as $\mathrm{Cu}(\mathrm{II}), \mathrm{Ni}(\mathrm{II}), \mathrm{Zn}(\mathrm{II}), \mathrm{Co}(\mathrm{II}), \mathrm{Ca}(\mathrm{II})$ and $\mathrm{Fe}(\mathrm{III})$ [5]. Metal affinity approach has unique advantages, such as cheapness of metal ions and reusability behaviour of metal affinity support [6]. IMAC also exhibits high recovery yields under the mild and non-denaturing elution conditions $[7,8]$.

Cryogels are the one of the intensively used new generation polymeric network matrices and were widely used in various biotechnological applications, such as biocatalysis, bioseparations and biomedical purposes. Cryogels can be easily prepared at subzero conditions by using polymerizable monomers, and thus, this process is called as cryopolymerization technique. At these polymerization conditions, most of the solvent (usually water) is in frozen state and monomers of the polymerization mixture are concentrated in non-frozen micro-solvent phase. Frozen ice crystals act as a porogen and create wide-open pores, which are the main characteristics of the cryogel structure. These pores are interconnected and create continuous pore backbone along with the cryogel structure [9]. Due to these large and interconnected macropores, substrate or biologically active molecules can be diffused fast and easily along with the cryogelic matrix. One of the main advantageous behaviours of the cryogels is that they are highly compatible with aqueous environments and thus, catalytic enzymatic reactions can take place easily and fast [10]. Cryogels were used as immobilized metal affinity supports and were applied for various studies, such as separation of recombinant proteins, environmental separations and enzyme immobilization applications [11-14].

Amyloglucosidase or glucoamylase (EC 3.2.1.3) is a hydrolytic enzyme, which breaks down the $\alpha(1 \rightarrow 4)$ and $\alpha(1 \rightarrow 6)$ linkages of oligosaccharides and starch [15]. The enzyme starts the hydrolysis process from the non-reducing edge of the starch and removes consecutive glucose units. Some certain varieties of Aspergillus niger are used for the commercial isolation of amyloglucosidase. This enzyme has diverse valuable industrial applications, such as dextrose production, baking industry, brewing of low-calorie beer and 
whole grain hydrolysis for alcohol industry [16]. There are many papers, which use IMAC techniques for reversible amyloglucosidase immobilization [17-21].

Metal chelate adsorption process is one of the non-covalent immobilization technique. In this technique, enzymes or bioactive molecules are adsorbed onto a metal-chelate adsorbent and this method was deeply applied as an alternative for the covalent approach due to its time saving behaviour and simple operation capabilities. These IMAC supports can also be reused after desorption of adsorbed species, and thus, total expense of the adsorption process is decreased, and produce lower residues [22-24].

In the present study, IMAC-modified cryogels were prepared by cryopolymerization of the structural monomer acrylamide (AAm) and the functional monomer glycidyl methacrylate (GMA), and then modified with IMAC ligand IDA. Synthesized poly(AAm-GMA)-IDA cryogels were then chelated with $\mathrm{Cu}^{2+}$ ions. These $\mathrm{Cu}$ (II) chelated cryogels (poly(AAm-GMA)-IDA-Cu ${ }^{2+}$ cryogels) were used for the reversible immobilization amyloglucosidase, and applied for the hydrolysis of starch. Although there are few studies for reversible adsorption of amyloglucosidase onto cryogel supports, this is the first study in which amyloglucosidase was reversibly adsorbed onto metal-chelated cryogels. These IMAC cryogels served good opportunities for metal chelate adsorption of amyloglucosidase, and collapsed advantageous behaviours of cryogels and IMAC process.

\section{Materials and methods}

\subsection{Materials}

Amyloglucosidase (EC 3.2.1.3) from Aspergillus niger, starch (soluble), AAm, GMA, IDA, N, $\mathrm{N}^{\prime}$-methylene-bis(acrylamide) (MBAAm), $\mathrm{N}^{\prime}, \mathrm{N}^{\prime}, \mathrm{N}^{\prime}, \mathrm{N}^{\prime}$-tetramethylenediamine (TEMED), ammonium persulphate (APS) and $\mathrm{CuSO}_{4} \cdot 5 \mathrm{H}_{2} \mathrm{O}$ were purchased from Sigma Chemical Co. (St. Louis, USA). The other chemicals were of analytical grade and supplied from Merck (Darmstadt, Germany). The ultrapure deionized water $(18.2 \mathrm{~m} \Omega \mathrm{cm})$ was purified by using Millipore Simplycity ${ }^{\circledR}$.

\subsection{Preparation of poly(AAm-GMA)-IDA-C $\mathrm{u}^{2+}$ cryogels}

Poly(AAm-GMA) cryogels were synthesized by the method of our recent publication [25]. In this polymerization method, AAm and GMA were used as a structural and functional monomers, respectively. Polymerization was carried out with free radical polymerization technique by using APS and TEMED as the initiator and activator pair, respectively. MBAAm was used as a cross-linker, while water acted as pore-former. Detailed polymerization recipe is explained as follows: an initial monomer solution was prepared by dissolving $28.3 \mu \mathrm{l}$ of GMA and $0.71 \mathrm{~g}$ of AAm in $5.0 \mathrm{ml}$ of distilled water. Cross-linker solution was prepared by dissolving
$0.25 \mathrm{~g}$ of MBAAm in $10.0 \mathrm{ml}$ of distilled water. Monomer and cross-linker solutions were mixed and radicalic polymerization reaction was initiated by adding $25 \mu \mathrm{l}$ of TEMED and $20 \mathrm{mg}$ of APS. This polymerization solution was immediately transferred to a cylindrical column and then incubated for $24 \mathrm{~h}$ at $-12^{\circ} \mathrm{C}$. At the end of the polymerization period, cryogels were defrosted and rinsed 3 times with $250 \mathrm{ml}$ of water. Metal-chelating ligand IDA was covalently attached to the cryogel backbone to introduce the active chelating groups for $\mathrm{Cu}(\mathrm{II})$. For this purpose, IDA solution $(50.0 \mathrm{ml}$, $10.0 \mathrm{mg} \mathrm{ml}^{-1}, \mathrm{pH} 11.0$ ) was reacted with cryogel column in continuous mode at $75^{\circ} \mathrm{C}$ for $6 \mathrm{~h}$ [26-28]. At the end of this covalent attachment period, functionalized cryogels were washed with acetic acid (5\%) and distilled water to remove the unreacted free IDA molecules. $\mathrm{Cu}$ (II) ions were chelated to the IDA-modified cryogel in continuous mode by using a peristaltic pump. Briefly, a solution of $\mathrm{CuSO}_{4} \cdot 5 \mathrm{H}_{2} \mathrm{O}$ ( $0.1 \mathrm{M}$, in $\mathrm{pH} 4.0$ acetate buffer) was passed through the cryogel column at $25^{\circ} \mathrm{C}$ for $2 \mathrm{~h}$. Here, $\mathrm{Cu}$ (II) ions were chelated with the functional IDA ligands of the polymeric cryogel column. Finally, poly(AAm-GMA)-IDA- $\mathrm{Cu}^{2+}$ cryogels were washed with water and stored at $4{ }^{\circ} \mathrm{C}$ in sodium azide solution $(0.02 \%)$ to protect the cryogel from microbial contamination.

\subsection{Characterization of $\mathrm{Cu}^{2+}$-chelated poly(AAm-GMA)- IDA cryogels}

The main chemical characterization of functional groups of the prepared $\mathrm{Cu}^{2+}$-chelated poly(AAm-GMA)-IDA cryogels was carried out with Fourier transform infrared (FTIR) spectroscopy by using a FTIR spectrophotometer (Varian FTS 7000, USA). FTIR samples were prepared by drying and powdering the cryogels, and samples were mixed with IR grade $\mathrm{KBr}$ to press the sample into a pellet form. Pellets were mounted to the FTIR device and results were analysed. Surface morphology, pore structure and pore size of the cryogel were investigated by scanning electron microscopy (SEM) (Philips XL-30S FEG, the Netherlands). For SEM analysis, inner part of the cryogel was plucked from the cryogel column and mounted in the SEM device, and then, SEM pictures of the samples were taken. Atomic composition and chelated amount of $\mathrm{Cu}$ (II) ions were examined by using energy-dispersive X-ray spectroscopy (EDX) analysis (Leo EVO40, Carl Zeiss, NTS, USA) with dried cryogel samples. Obtained EDX spectrum was used to calculate the chelated amount of $\mathrm{Cu}$ (II) per mass of cryogel [10].

\subsection{Amyloglucosidase adsorption and desorption studies}

Adsorption process for amyloglucosidase onto $\mathrm{Cu}^{2+}$-chelated poly(AAm-GMA)-IDA cryogels was investigated in a continuous system by using a column. A typical adsorption process is identified as follows: first of all, synthesized cryogel column was rinsed with water and then, equilibrated using 
acetate buffer $(50.0 \mathrm{mM}, \mathrm{pH} 5.0)$. Then, aqueous solution of amyloglucosidase $(5.0 \mathrm{ml})$ was passed through the cryogel column for $2 \mathrm{~h}$. Quantity of adsorption was calculated by comparing the initial and final amyloglucosidase concentrations in the adsorption medium determined spectrophotometrically at $280 \mathrm{~nm}$. Effects of medium $\mathrm{pH}$, initial amyloglucosidase concentration, temperature and ionic strength on the amyloglucosidase adsorption were examined to determine the optimum amyloglucosidase adsorption conditions. For this purposes, $\mathrm{pH}$ of the amyloglucosidase solution was changed between 4.0 and 8.0, while initial amyloglucosidase concentration was investigated in the range of $0.1-1.0 \mathrm{mg} \mathrm{ml}^{-1}$. Effect of medium temperature was also studied by testing different temperatures $\left(4-55^{\circ} \mathrm{C}\right)$. Ionic strength of the adsorption medium was changed between 0.01 and $1.0 \mathrm{M}$ by using solid $\mathrm{NaCl}$ to test the effect of ionic strength on the adsorption efficiency of the amyloglucosidase onto cryogel column.

Adsorbed amyloglucosidase was desorbed from the cryogel column by using $\mathrm{NaCl}$ solution $(1.0 \mathrm{M})$. For this, $5.0 \mathrm{ml}$ of desorption agent was subjected with column for 1 $\mathrm{h}$ and desorbed amount of amyloglucosidase was detected in the desorption medium. Reusability profile is an important parameter for practical usage of the synthesized columns and thus, reusability of the $\mathrm{Cu}^{2+}$-chelated poly(AAm-GMA)-IDA cryogels was tested for 50 successive adsorption/desorption cycles by using the same cryogel [25].

\subsection{Determination of amyloglucosidase activity}

Amyloglucosidase activity was examined by using the Bernfeld method [29]. Briefly, $0.5 \mathrm{ml}$ of enzyme preparation and $0.5 \mathrm{ml}$ starch solution (1.0\% in $\mathrm{pH} 5.0$ acetate buffer) were mixed and incubated at $25^{\circ} \mathrm{C}$ for $5 \mathrm{~min}$. At the end of the incubation period, enzymatic reaction was inactivated by adding $1.0 \mathrm{ml}$ of DNS reagent (dinitrosalicylic acid). Then, reaction mixture was incubated again for $5 \mathrm{~min}$ in a boiling water bath and then cooled to room temperature. After adding $10.0 \mathrm{ml}$ distilled water, absorbance of the final product was read at $540 \mathrm{~nm}$ by using a spectrophotometer. The degree of starch digestion was determined by using a calibration curve established by different concentrations of glucose. One unit of amyloglucosidase activity was determined as the amount of enzyme, which liberates $1.0 \mu \mathrm{mol}$ of glucose from starch within a minute under the assay condition $[30,31]$.

Reaction end products of the starch hydrolysis were investigated and confirmed by thin layer chromatography (TLC). For this; starch, hydrolysed starch and glucose standards were spotted on a TLC plate (Alugram ${ }^{\circledR}$ SIL G UV U25 , $5 \times 10 \mathrm{~cm}$, Germany) and then developed by using a $\mathrm{n}$ butanol/ethanol/water $(5: 3: 2, \mathrm{v} / \mathrm{v} / \mathrm{v})$ solvent system. Sugar samples were visualized by spraying an orcinol solution $(0.2 \%(\mathrm{w} / \mathrm{v})$ in sulphuric acid:methanol $(1: 90 \mathrm{v} / \mathrm{v}))$ and then heated [32].

\section{Results and discussion}

\subsection{Characterization of poly(AAm-GMA)-IDA-C $C u^{2+}$ cryogels}

As a new member of monolithic columns, cryogels exhibit unique advantageous behaviours over the conventional column materials such as, wide-open pore structures, short diffusion path, low pressure drops and short residence time. After its pioneering applications for microbial cell separation [33], cryogels were found a good position for direct purification of biomolecules $[34,35]$ and even crude cell homogenates [36-38]. Additionally, cryogels can be easily modified with various functionalities by using different types of ligands and can be applied for the affinity adsorption of biomolecules for biotechnological applications. One of the intensively used functional groups for modification purposes is epoxy-bearing monomers. Epoxy-carrying monomers were deeply applied because of their fast, easy and simple reaction properties [33,39-42]. Polymerization with epoxy-bearing monomers yields free epoxy groups for the modification with different kinds of ligands. In the present study, GMA was chosen as an epoxy-carrying functional monomer and polymerized with AAm monomer by using cryopolymerization technique. Synthesized poly(AAm-GMA) cryogels were then further modified with chelating agent IDA and then chelated with $\mathrm{Cu}^{2+}$ ions. These newly synthesized metal chelate affinity materials were used for the adsorption of amyloglucosidase. A schematic presentation for the preparation of $\mathrm{Cu}^{2+}$-chelated poly(AAm-GMA)-IDA cryogels is demonstrated in figure 1 .

Figure 2 demonstrates the FTIR spectra of poly(AAmGMA) and poly(AAm-GMA)-IDA cryogels. As clearly seen here, $-\mathrm{CH}_{3}$ and $\mathrm{C}=\mathrm{O}$ stretching bands are located around 3400 and $1700 \mathrm{~cm}^{-1}$, respectively. Carbonyl stretching bands of $\mathrm{C}=\mathrm{O}$ are also seen at around $1200 \mathrm{~cm}^{-1}$. Amide I and II adsorption bands are located at around 1650 and $1550 \mathrm{~cm}^{-1}$, respectively. Additionally, valence vibration bands of $\mathrm{C}-\mathrm{N}$ are located around $1450 \mathrm{~cm}^{-1}$. SEM pictures of the synthesized poly(AAm-GMA)-IDA cryogels are demonstrated in figure 3 . As clearly seen here, overall cryogel structure is highly porous and pore diameter is about $3-10 \mu \mathrm{m}$. Spongelike structure of the cryogel is also seen here. EDX spectrum of $\mathrm{Cu}^{2+}$-chelated poly(AAm-GMA)-IDA cryogels is demonstrated in figure 4. As expected, the cryogel contained C, N, $\mathrm{O}$ and $\mathrm{Cu}$ atoms. $\mathrm{Cu}$ atoms in this spectrum, was also supported that $\mathrm{Cu}^{2+}$-chelated poly(AAm-GMA)-IDA cryogels were synthesized successfully. Chelated amount of $\mathrm{Cu}^{2+}$ was also calculated with the help of EDX findings and found to be $225.02 \mu \mathrm{mol} \mathrm{g}^{-1}$ polymer.

\subsection{Amyloglucosidase adsorption and desorption}

IMAC works depend on the coordinative interactions between a 'Lewis acid' (an electron pair acceptor, in this method, a chelated metal ions) and an electron donor atom (N, O and S) located on the surface of the biomolecule structure. When 

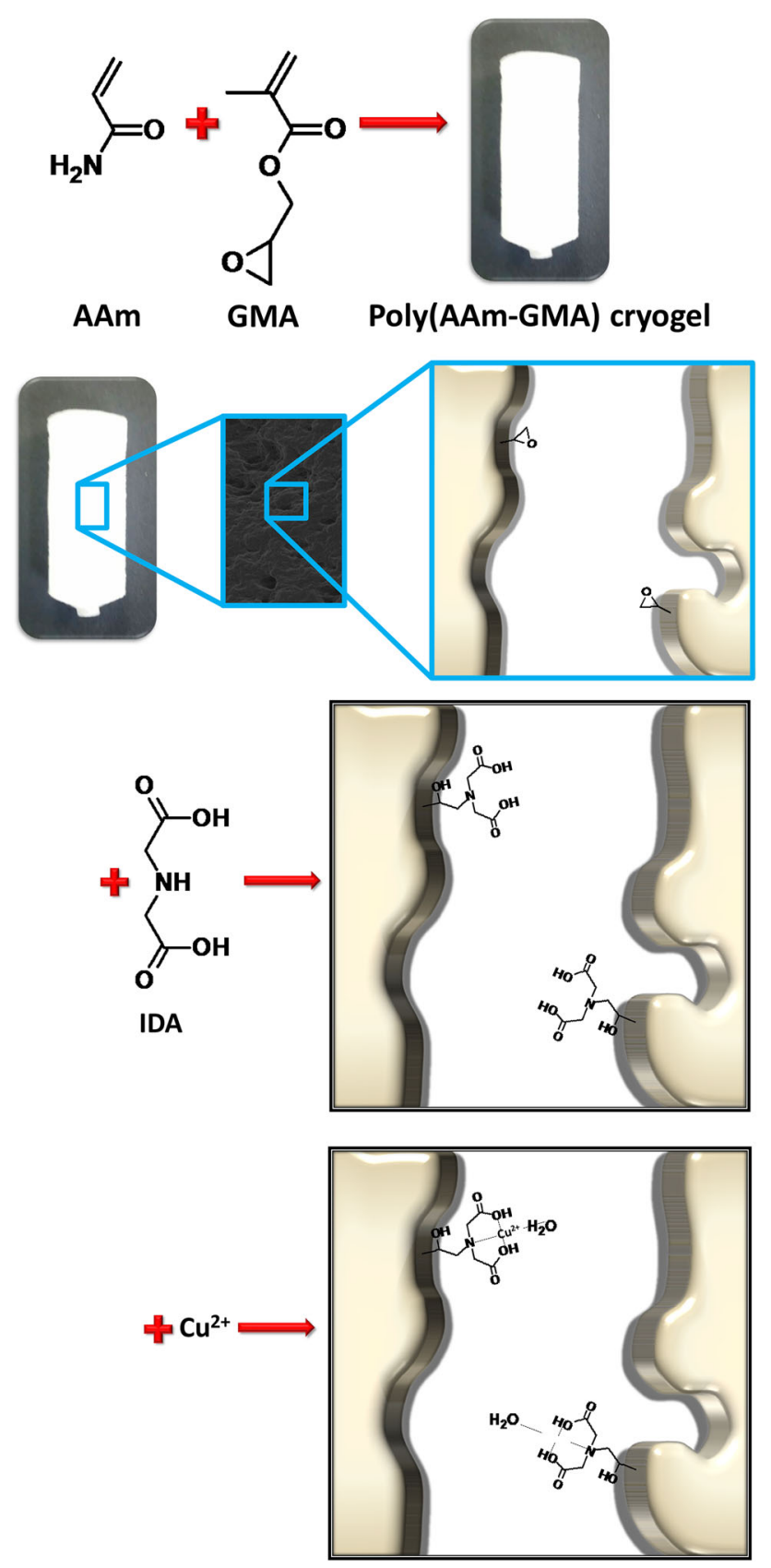

Figure 1. Schematic presentation for the preparation of poly(AAm-GMA)-IDA-Cu ${ }^{2+}$ cryogels.

dealing with protein, these surface groups are histidine (via imidazole group), tryptophan (via indoyl group) and cystein (via thiol group). Protein adsorption process is also supported by the other amino acids apart from the above mentioned ones, and this also depends on the local conformation of native protein structure [43].

Adsorption studies of amyloglucosidase onto $\mathrm{Cu}^{2+}$ chelated poly(AAm-GMA)-IDA cryogels were investigated with different medium pHs and findings are summarized in figure 5. As clearly seen here, the highest amyloglucosidase adsorption efficiency of $\mathrm{Cu}^{2+}$-chelated poly(AAm-GMA)IDA cryogel was observed by using pH 5.0 acetate buffer. At higher and lower $\mathrm{pH}$ values than $\mathrm{pH}$ 5.0, adsorption efficiency of $\mathrm{Cu}^{2+}$-chelated poly(AAm-GMA)-IDA cryogels decreased. At isoelectric point, proteins have no net charge within all protein structures. Isoelectric point of amyloglucosidase from $A$. niger was reported as $\mathrm{pH} 4.0$ and this enzyme has net positive charge at more acidic pHs than 4.0 and demonstrates negative charge at more basic regions [44]. It can be concluded from this result that electrostatic interaction also contributed to the metal-coordination interactions. At this $\mathrm{pH}$, ionization state of the surface amino acid residues of the enzyme molecule along with the conformational state of the enzyme structure also played an important role for the adsorption efficiency. The effect of amyloglucosidase concentration on amyloglucosidase adsorption onto $\mathrm{Cu}^{2+}$-chelated poly(AAm-GMA)-IDA cryogels is demonstrated in figure 6 . As seen in this adsorption profile, adsorbed amount of amyloglucosidase increased with increasing amyloglucosidase concentration and then reached a plateau value $\left(3.48 \mathrm{mg} \mathrm{g}^{-1}\right.$ cryogel) after amyloglucosidase concentration of $0.75 \mathrm{mg} \mathrm{ml}^{-1}$. Initial sharp steep of this adsorption profile notify that the affinity between amyloglucosidase molecules and $\mathrm{Cu}^{2+}$-chelated cryogels was very high.

Adsorption types are defined mainly by using the adsorption isotherms. A plot is constructed by using the adsorbed amount of amyloglucosidase $C\left(q_{\mathrm{e}}\right)$ against the equilibrium amyloglucosidase concentration $\left(C_{\mathrm{e}}\right)$. The most appealed isotherms are Langmuir and Freundlich models that used to understand the type of adsorption process. Langmuir model notify that there are well-defined binding sites with equivalent energy for adsorption process, all binding sites are located far from each other, there is no cross-interaction between these binding sites and bind only one molecule. Because of these properties, energies and enthalpies are equal and Langmuir model can be expressed as equation (1):

$$
q_{\mathrm{e}}=\frac{q_{\mathrm{m}} K_{\mathrm{a}} C_{\mathrm{e}}}{1+K_{\mathrm{a}} C_{\mathrm{e}}}
$$

This equation can be transformed to linear form as equation (2):

$$
\left(\frac{C_{\mathrm{e}}}{q_{\mathrm{e}}}\right)=\left(\frac{C_{\mathrm{e}}}{q_{\mathrm{m}}}\right)+\left(\frac{1}{q_{\mathrm{m}} K_{\mathrm{a}}}\right)
$$

here $K_{\mathrm{a}}$ is the constant for adsorption equilibrium; $C_{\mathrm{e}}$ the concentration of unadsorbed substance, $q_{\mathrm{e}}$ the concentration of adsorbed substance and $q_{\mathrm{m}}$ the maximum amount of adsorption per unit weight of adsorbent.

Another form of Langmuir for adsorption process is Freundlich isotherm. In this adsorption model, adsorption takes place on heterogeneous surface of the adsorbent with non-uniform distribution of the adsorbed substance. In contrast to the Langmuir model, Freundlich model allows multilayer adsorption. 


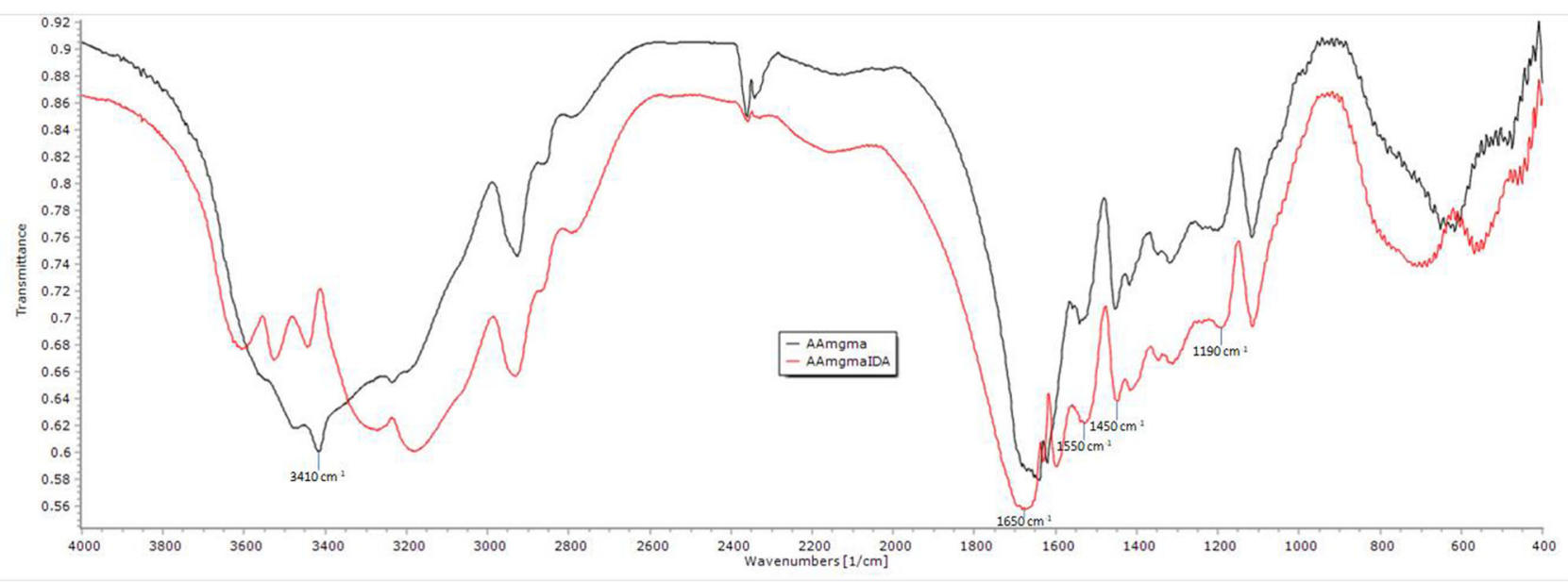

Figure 2. FTIR spectra of poly(AAm-GMA) and poly(AAm-GMA)-IDA cryogels.

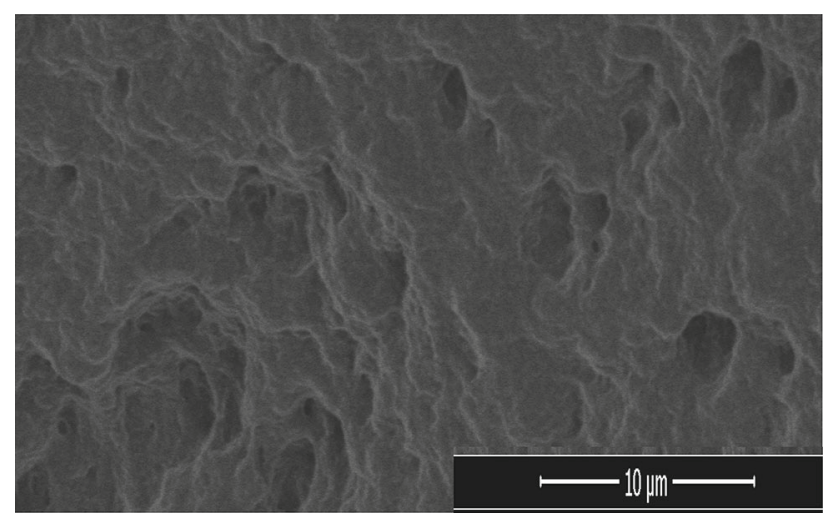

Figure 3. SEM picture of poly(AAm-GMA)-IDA cryogels.

Freundlich isotherm and its linear form are given by equations (3) and (4), respectively;

$$
\begin{aligned}
& q_{\mathrm{e}}=K_{\mathrm{f}} C_{\mathrm{e}}^{1 / n}, \\
& \ln q_{\mathrm{e}}=\ln K_{\mathrm{f}}+\frac{1}{n} \ln C_{\mathrm{e}},
\end{aligned}
$$

here $q_{\mathrm{e}}$ is the amount of adsorbed species at equilibrium; $C_{\mathrm{e}}$ the equilibrium of non-adsorbed amount; $K_{\mathrm{f}}$ and $n$ are the constants for Freundlich model and $K_{\mathrm{f}}$ related to the adsorption capacity, $n$ a marker for the intensity of adsorption [45].

The $q_{\mathrm{m}}$ value for the Langmuir model was found to be 7.14 $\mathrm{mg} \mathrm{g}^{-1}$, while $K_{\mathrm{f}}$ for Freundlich model was $3.36 \mathrm{mg} \mathrm{g}^{-1}$. It can be concluded from these results that $\mathrm{Cu}^{2+}$-chelated poly(AAm-GMA)-IDA cryogels demonstrated good affinity for amyloglucosidase. The $R^{2}$ values of Langmuir and Freundlich isotherms were found to be 0.5166 and 0.9719 , respectively. As comparing these results, it can be suggested that Freundlich isotherm was valid for this adsorption process, adsorption regions on the cryogel were heterogeneous and there were multi-layered adsorption for amyloglucosidase adsorption.

The effect of the medium temperature on the adsorption of amyloglucosidase onto $\mathrm{Cu}^{2+}$-chelated poly(AAm-GMA)IDA cryogels was investigated in the temperature range of $4-55^{\circ} \mathrm{C}$ and findings are demonstrated in figure 7 . As seen here, adsorbed amount of amyloglucosidase increased with increasing temperature up to $25^{\circ} \mathrm{C}$ and then, decreased slowly. This temperature profile generally occurs when the adsorbed species are biomolecules. At high temperatures, the interaction between amyloglucosidase and $\mathrm{Cu}$ (II) ions reduced because of the conformational changes of the enzyme structure, which takes place at high temperatures. Effect of ionic strength on the adsorption of amyloglucosidase was also investigated by increasing $\mathrm{NaCl}$ concentrations (figure 8). As clearly seen here, adsorption capacity of $\mathrm{Cu}^{2+}$-chelated poly(AAm-GMA)-IDA cryogels decreased with increasing ionic strength. High ionic strength weakened the interactions between the amyloglucosidase and metal chelate adsorbent by creating the repulsive electrostatic forces between the metal ligands and the enzymes.

Additionally, activities of free and immobilized enzymes were checked with the series of control experiments by using Bernfeld method, to show the efficiency of the immobilized form of amyloglucosidase. For this purpose, a plain cryogel was synthesized by the same methodology without enzyme immobilization. $\mathrm{Cu}$ (II)-free cryogels and copperimbedded ligand-free cryogels were also prepared and used as a support material for amyloglucosidase immobilization. Activities of these controls were compared with free enzyme and amyloglucosidase immobilized $\mathrm{Cu}^{2+}$-chelated poly(AAm-GMA)-IDA cryogels. In these control experiments, immobilized amyloglucosidase onto $\mathrm{Cu}^{2+}$-chelated poly(AAm-GMA)-IDA cryogel protected almost $50 \%$ of initial activity of free enzyme. However, ligand-free $\mathrm{Cu}(\mathrm{II})-$ imbedded cryogel and $\mathrm{Cu}$ (II) free cryogel displayed 0.06 and $1.83 \%$ activities, respectively. The plain amyloglucosidase 


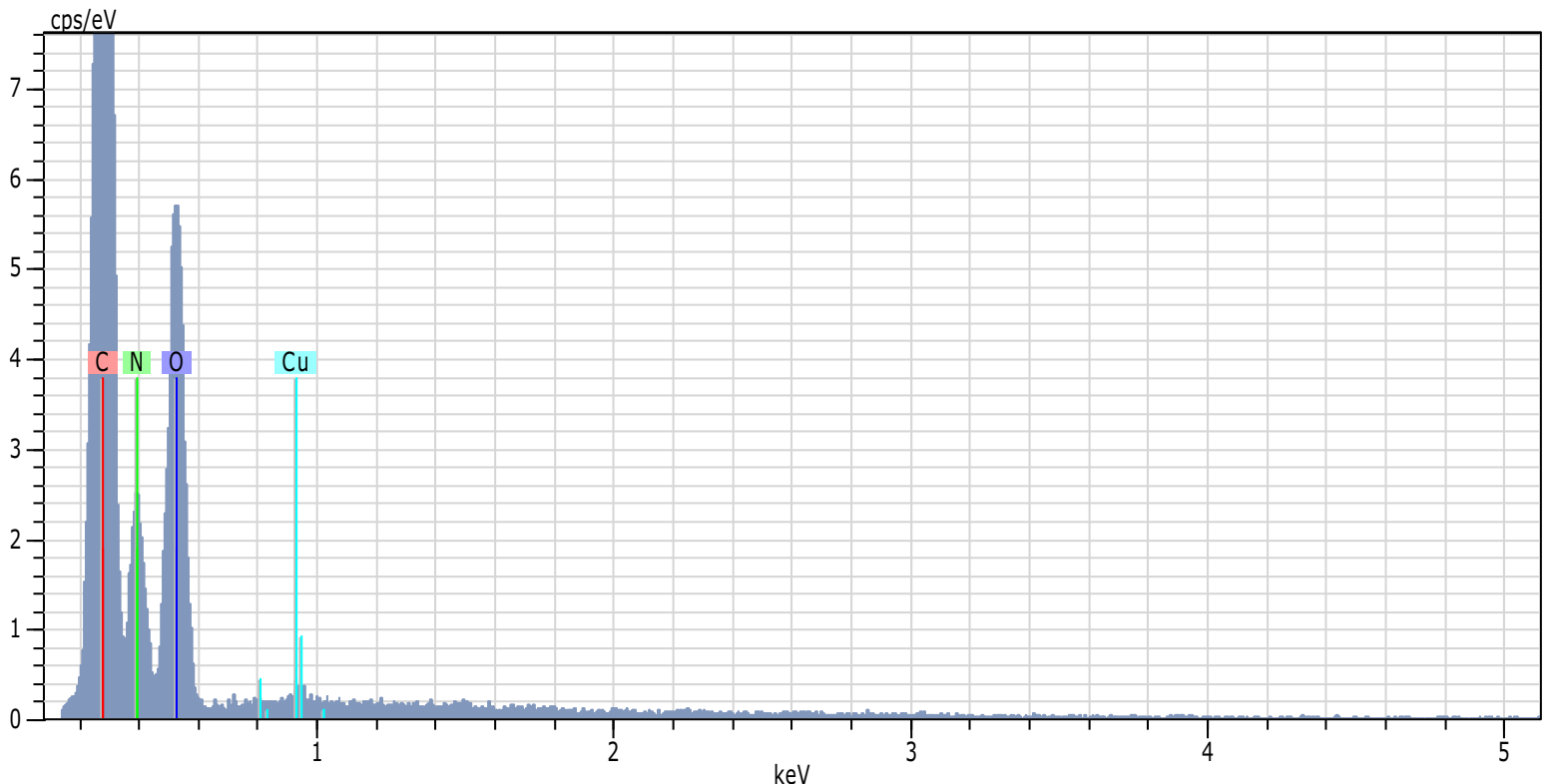

Figure 4. EDX spectrum of $\mathrm{Cu}^{2+}$-chelated poly(AAm-GMA)-IDA cryogels.

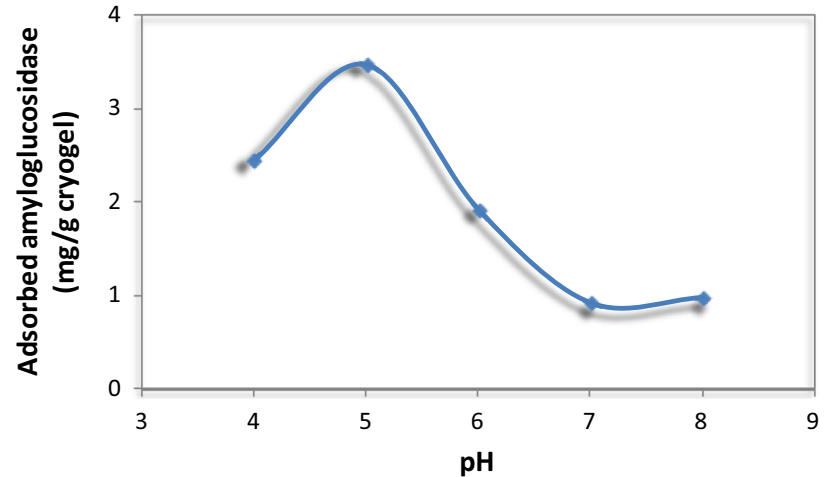

Figure 5. Effect of medium $\mathrm{pH}$ on the adsorption of amyloglucosidase onto $\mathrm{Cu}^{2+}$-chelated poly(AAm-GMA)-IDA cryogels.

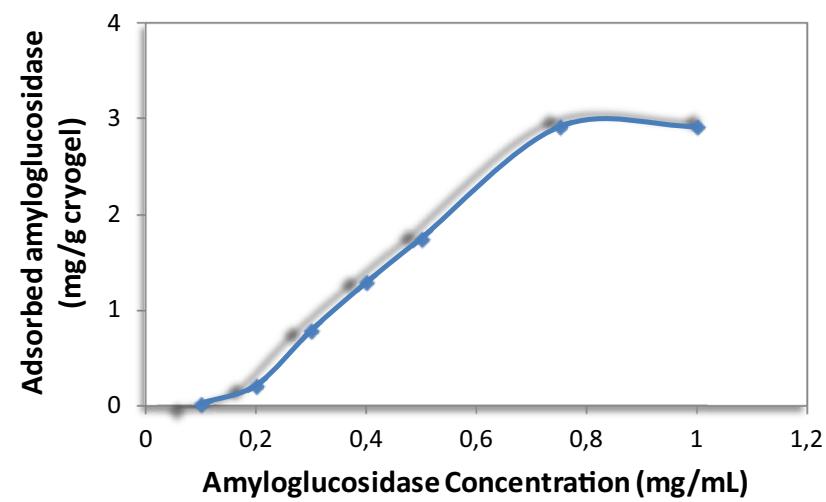

Figure 6. Effect of amyloglucosidase concentration on the adsorption of amyloglucosidase onto $\mathrm{Cu}^{2+}$-chelated poly(AAm-GMA)IDA cryogels.

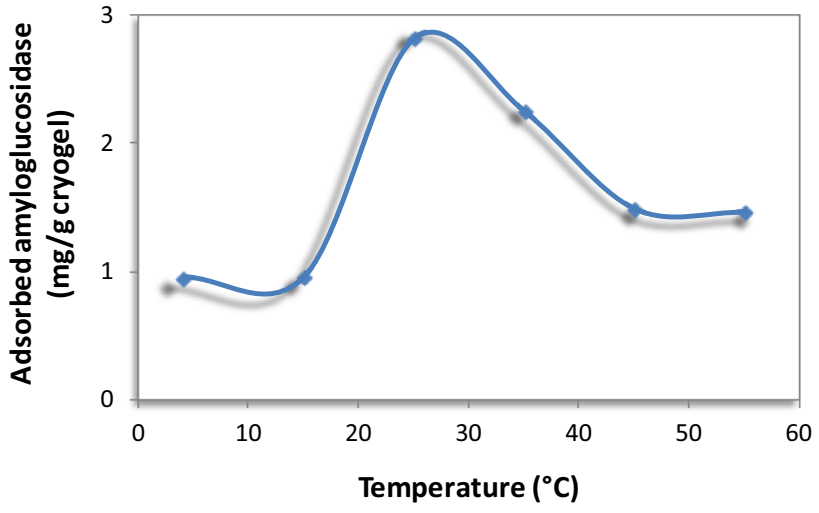

Figure 7. Effect of medium temperature on the adsorption of amyloglucosidase onto $\mathrm{Cu}^{2+}$-chelated poly(AAm-GMA)-IDA cryogels.

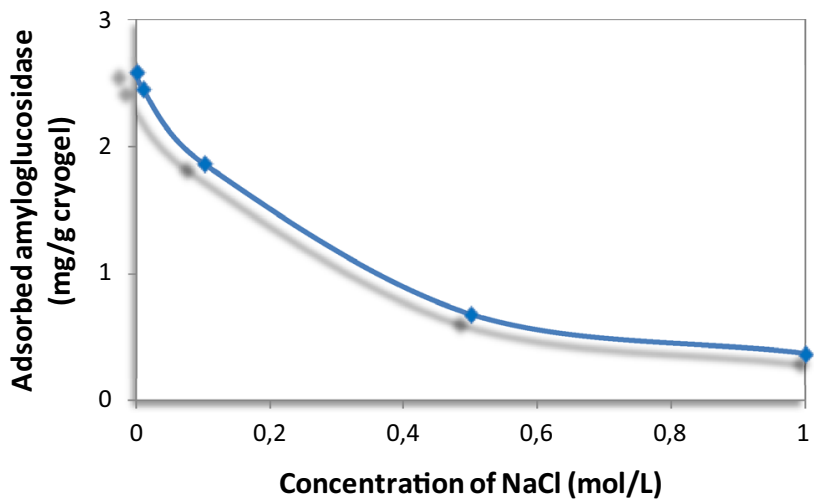

Figure 8. Effect of medium ionic strength on the adsorption of amyloglucosidase onto $\mathrm{Cu}^{2+}$-chelated poly(AAm-GMA)-IDA cryogels. 
(a)

(b)
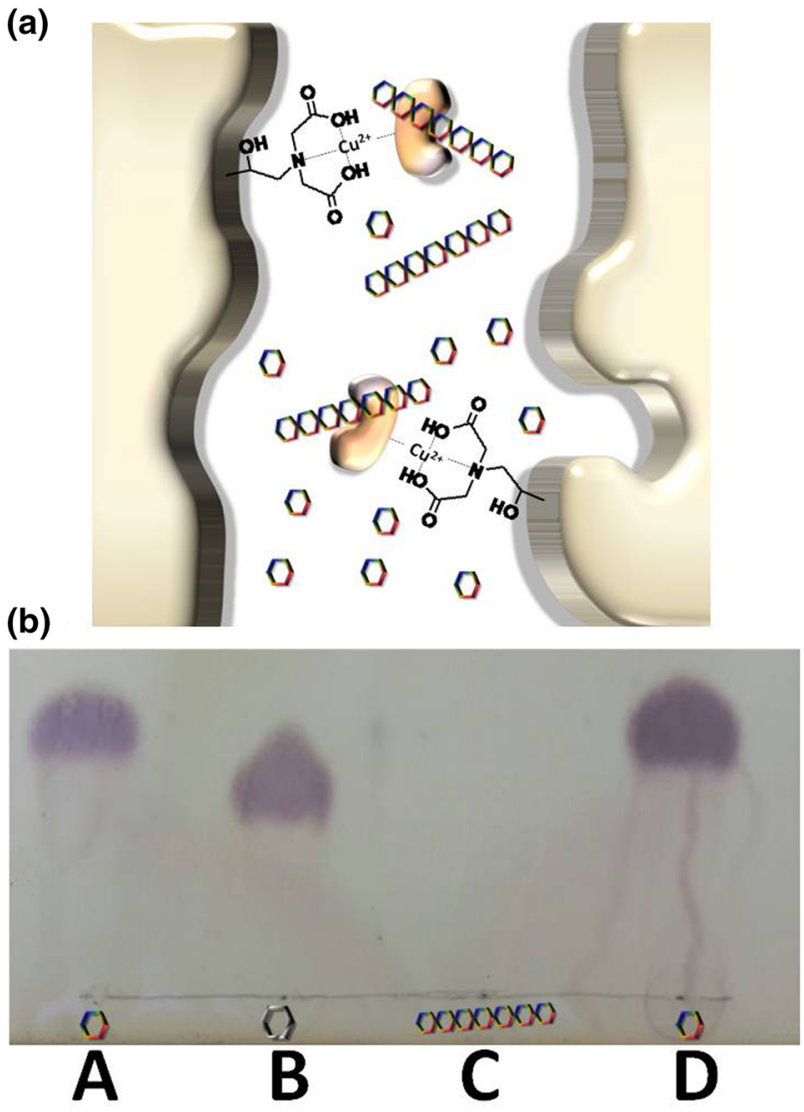

Figure 9. TLC run of (A) standard glucose, (B) maltose, (C) starch and (D) hydrolyzed hydrolysed starch.

activity of enzyme free $\mathrm{Cu}^{2+}$-chelated poly(AAm-GMA)IDA cryogel showed $0.12 \%$ of initial activity. As stated here, amyloglucosidase-free cryogel and ligand-free cryogels have demonstrated very low activity. Although immobilized form of amyloglucosidase protected $50 \%$ of its initial activity, this immobilized enzyme preparation was successfully applied for the continuous hydrolysis of starch.

\subsection{Elution and reusability of $\mathrm{Cu}^{2+}$-chelated poly(AAm-GMA)-IDA cryogels}

Elution of the adsorbed molecules and regeneration of the polymeric adsorbent are very important parameters for the practical usage of the synthesized polymeric support material in bioseparations studies. As ideal, all adsorbed species should be desorbed efficiently from the support and support material should be reused repeatedly. In this study, more than $95 \%$ of adsorbed amyloglucosidase was desorbed from the cryogel support easily by using $1.0 \mathrm{M} \mathrm{NaCl}$ as a desorption agent. Reusability profile of the $\mathrm{Cu}^{2+}$-chelated poly(AAm-GMA)-IDA cryogels was studied by using the same cryogel for 50 successive adsorption/desorption cycles, and at the end of the 50th reuse, adsorption capacity of the cryogel was not significantly decreased and stayed stable.
As preparative application of immobilized form of amyloglucosidase, continuous starch hydrolysis studies were carried out by a column system (figure 9a). For this, starch solution was passed through the cryogel column and activity of the immobilized amyloglucosidase was investigated by Bernfeld method. The final products were also visualized by TLC. The released glucose amount was calculated as $13.32 \mathrm{mg} \mathrm{ml}^{-1}$ for $5 \mathrm{~min}$ of hydrolysis time. The products along with the standards starch and glucose were demonstrated by TLC (figure 9b) and as seen here, products compose of glucose produced by the hydrolysis of starch. These results demonstrated that $\mathrm{Cu}^{2+}$-chelated poly(AAm-GMA)IDA cryogels can be successfully applied for the separation or immobilization of amyloglucosidase without any enzymatic activity loss.

\section{Conclusion}

A new metal-chelating platform was developed for reversible adsorption of amyloglucosidase. IMAC techniques were intensively applied in various bioseparation studies. IMAC offers high recovery yields for biomolecule purifications. Purification process in IMAC is carried out in milder conditions, and elution of the adsorbed species is very easy by using non-denaturing agents. IMAC ligand of this presented work was IDA, and it was covalently attached onto surface of the poly(AAm-GMA) cryogels. As a new monolithic chromatographic support material, cryogels serve a good capability of the purification and/or separation of biomolecules. Cryogelic column supports can be prepared easily with polymerizable precursors, and can be modified with various ligands to form different surface characteristics and functionalities. Chemical and physical stabilities of cryogels are also very high and large interconnected macroporous structure gives unique advantages for bioseparation process. In the present work, poly(AAm-GMA)-IDA cryogels were first synthesized and then chelated with $\mathrm{Cu}^{2+}$ ions. Prepared poly(AAmGMA)-IDA-Cu ${ }^{2+}$ cryogels were then used for the reversible adsorption of amyloglucosidase. Adsorption efficiency of the cryogel was investigated and reusability property of the support material was also studied. Activity of the immobilized form of amyloglucosidase was also tested and the products of the starch hydrolysis were demonstrated by TLC. As a closing sentence, it can be asserted that this metal-chelated cryogel platform represents a promising route for efficient amyloglucosidase purification, shows potential for column application to hydrolyse amyloglucosidase and it is expected to pave the way for diverse applications of bioseparations studies.

\section{References}

[1] Porath J, Carlsson J, Olsson I and Belfrage G 1975 Nature 258 598 
[2] Gupta M N, Jain S and Roy I 2002 Biotechnol. Prog. 1878

[3] Ivanov A E, Galaev I Y, Kazakov S V and Mattiasson B 2001 J. Chromatogr. A 907115

[4] Denizli A, Alkan M, Garipcan B, Özkara S and Pişkin E 2003 J. Chromatogr. B 79593

[5] Yabutani T, Sumi H, Nakamura T, Akatsuki S and Thuy L T X 2012 Anal. Sci. 28463

[6] Altıntaş E B, Yavuz H, Say R and Denizli A 2006 J. Biomater. Sci. Polym. Ed. 17213

[7] Uygun D A, Şenay R H, Türkcan C, Akgöl S and Denizli A 2012 Appl. Biochem. Biotechnol. 1681528

[8] Lin P-C, Lin S-C and Hsu W-H 2008 J. Chin. Inst. Chem. Eng. 39389

[9] Lozinsky V I, Galaev I Y, Plieva F M, Savina I N, Jungvid H and Mattiasson B 2003 Trends Biotechnol. 21 445

[10] Uygun M, Akduman B, Ergönül B, Uygun D A, Akgöl S and Denizli A 2015 J. Biomater. Sci. Polym. Ed. 26 1112

[11] Bibi N S, Singh N K, D’souza R N, Aasim M and FernándezLahore M 2013 J. Chromatogr. A 1272145

[12] Onnby L, Giorgi C, Plieva F M and Mattiasson B 2010 Biotechnol. Prog. 261295

[13] Efremenko E, Votchitseva Y, Plieva F, Galaev I and Mattiasson B 2006 Appl. Microbiol. Biotechnol. 70558

[14] Kumar A, Bansal V, Andersson J, Roychoudhury P K and Mattiasson B 2006 J. Chromatogr. A 110335

[15] Reddy P S, Rani D J and Sulthana S 2011 J. Pure Appl. Microbiol. 5167

[16] James J A and Lee B H 1997 J. Food Biochem. 211

[17] Wang F, Guo C, Liu H-Z and Liu C-Z 2007 J. Mol. Catal. B 481

[18] Osman B, Kara A and Beşirli N 2011 J. Macromol. Sci. Part A 48387

[19] Zhao G, Li Y, Wang J and Zhu H 2011 Appl. Microbiol. Biotechnol. 91591

[20] Zhao G, Wang J, Li Y, Huang H and Chen X 2012 Biochem. Eng. J. 68159

[21] Baydemir G, Derazshamshir A, Andaç M, Andaç C and Denizli A 2012 J. Appl. Polym. Sci. 126575

[22] Torres R, Pessela B C C, Mateo C, Ortiz C, Fuentes M, Guisan J M et al 2004 Biotechnol. Progr. 201297

[23] Marin-Zamoraa M E, Rojas-Melgarejoa F, Garcia-Canovasb F and Garcia-Ruiz P A 2006 J. Biotechnol. 126295
[24] Rebros M, Rosenberg M, Mlichova Z, Kristofikova L and Paluch M 2006 Enzyme Microb. Technol. 39800

[25] Uygun D A, Uygun M, Akgöl S and Denizli A 2015 Mat. Sci. Eng. C $\mathbf{5 0} 379$

[26] Zhou X, Liu D, Zhong L and Yang B 2011 Anal. Bioanal. Chem. 4011251

[27] Odabaşı M, Uzun L and Denizli A 2004 J. Appl. Polym. Sci. 93 2501

[28] Luo Q, Zou H, Xiao X, Gou Z, Kong L and Mao X $2001 \mathrm{~J}$. Chromatogr. A 926255

[29] Bernfeld P 1955 Methods in enzymology (New York: Academic) vol. I

[30] Milosavic N, Prodanovic R, Jovanovic S and Vujcic Z 2007 Enzyme Microb. Technol. 401422

[31] Wee L L, Annuar M S M, Ibrahim S and Chisti Y 2011 Chem. Eng. Commun. 1981339

[32] Altunbaş C, Uygun M, Uygun D A, Akgöl S and Denizli A 2013 Appl. Biochem. Biotechnol. 1701909

[33] Arvidsson P, Plieva F M, Savina I N, Lozinsky V I, Fexby S, Bülow L et al 2002 J. Chromatogr. A 97727

[34] Deraz S, Plieva F M, Galaev I Y, Karlsson E N and Mattiasson B 2007 Enzyme Microb. Technol. 40786

[35] Yan C, Shen S, Yun J, Wang L, Yao K and Yao S J 2008 J. Sep. Sci. 313879

[36] Yun J, Shen S, Chen F and Yao K 2007 J. Chromatogr. B 860 57

[37] Arvidsson P, Plieva F M, Lozinsky V I, Galaev I Y and Mattiasson B 2003 J. Chromatogr. A 986275

[38] Sun S, Tang Y, Fu Q, Liu Z, Guo L, Zhao Y et al 2012 Int. J. Biol. Macromol. 501002

[39] Plieva F M, Anderson J, Galaev I Y and Mattiasson B 2004 J. Sep. Sci. 27828

[40] La Fuente J L, Canamero P F and Fernandez-Garcia M 2006 J. Polym. Sci. 441807

[41] Altıntaş E B, Türkmen D, Karakoç V and Denizli A 2011 Colloids Surf. B: Biointerfaces $\mathbf{8 5} 235$

[42] Bereli N, Şener G, Altıntaş E B, Yavuz H and Denizli A 2010 Mater. Sci. Eng. C 30323

[43] Tishchenko G, Dybal J, Meszaroova J K, Sedlakova Z and Bleha M 2002 J. Chromatogr. A 954115

[44] Svensson B, Pedersen T G, Svendsen I B, Sakai T and Ottesen M 1982 Carlsberg Res. Commun. 4755

[45] Çimen D and Denizli A 2012 Colloids Surf. B: Biointerfaces 9329 